\title{
Teknolojik Devinimin Kentlere Getirmiş Olduğu Fırsat ve Tehditler: IoT Tabanlı Akıllı Kentler Üzerinden Bir Analiz ${ }^{* *}$
}

Opportunities and Threats Introduced by Technological Motion to Cities: An IoT-Based Analysis on Smart Cities

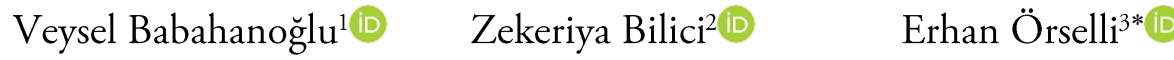 \\ ${ }^{1}$ Akçakoca Vocational School, Düzce University, Düzce, Turkey \\ ${ }^{2}$ Meram Vocational School, Necmettin Erbakan University, Konya, Turkey \\ ${ }^{3}$ Department of Political Science and Public Administration, Necmettin Erbakan University, Konya, Turkey
}

\begin{abstract}
Received: 15.07 .2020
Accepted: 01.09 .2020

This article was checked by intihal.net

ISSN: $2149-8598$

Öz

Bilgi ve iletişim teknolojilerinin gelişimi ve kent yaşamına adaptasyonu ile birlikte kentlerin akıllı hale gelmesi söz konusu olmuştur. Akıllı kentlerin ihtiyaçtan ve buna bağlı olarak bir vizyondan ortaya çıktığı söylenebilir. Çünkü kentsel mekanlarda yaşayan nüfusun yoğunluğu, çevre kirliliği, kaynakların yetersizliği, çarpık kentleşme, güvenlik ve trafik sıkışılığı gibi sorunların varlığı çözüm noktasında kentler üzerinde baskı kurmaktadır. Bu baskıdan kurtulmak, süreci yönetebilmek ve yaşam standartlarını artırmak isteyen kent yönetimleri sundukları servislere ve hizmetlere "Nesnelerin İnterneti (IoT)" cihazları entegre etme yoluna gitmektedir. Böylece kentlerde IoT yardımıyla birçok kentsel kamu hizmeti otomatikleştirilerek, daha etkin ve verimli sunulabilir hale gelmektedir. Ancak kentlerin akıllı hale gelmesi kentlere çeşitli firsatlar sunarken aynı zamanda bir dizi zorlukları ve tehditleri de beraberinde getirmektedir. IoT ile donatılan akıllı kentlerde özellikle kentlilerin yaşam kalitesinin artmasının yanında ciddi anlamda siber güvenlik problemleri de söz konusu olmaktadır. Bu bağlamda çalışmanın amacı yaşanan teknolojik devinimin kentler üzerindeki olumlu ve olumsuz etkisini IoT tabanlı akıllı kentler üzerinden incelemektir. Bu kapsamda çalışmada öncelikle akıllı kent kavramı ve bileşenleri incelenmiş, ardından teknolojik gelişmelerin kentler üzerindeki etkisi fırsat ve tehditler bağlamında değerlendirilmiştir. Çalışma nitel bir yöntemle oluşturulmuştur.
\end{abstract}

Anahtar Kelimeler: Akıllı Kent, Akıllı Kent Teknolojileri, Nesnelerin İnterneti (IoT), Fırsat, Tehdit

\section{Abstract}

With the help of the development in knowledge and communication along with adaptation to urban life, the idea of smart cities have become to fore stage. Smart cities can be said to come out by the need and the vision stemming from that need. Because, the existing problems such as: dense population in urban places, environmental pollution, insufficient sources, unplanned urbanization, security and traffic jam create a pressure on the cities, a solution to that is hindered. In order to get rid of the pressure; conduct the process and enhance the living conditions; city governors choose to integrate "Internet of Things (IoT)" in their services. Therefore, by means of IoT, many public services have become automated which led to more effective and fruitful services to come out. However, while cities' becoming smart offer various opportunities; on the other hand this situation creates great many threats and hardship in itself. Cities that are furnished with IoT instruments, while on the one hand particularly enhances quality life for the people living in urban places; on the other hand creates serious cyber security problems. Within this context, the aim of this study is to scrutinize the pros and cross effects of technological motion on smart cities in which IoT is installed. Within this framework, firstly the idea of smart cities and instruments is scrutinized and later on the pros and cross effects of technological advancement with regards to opportunities and threats are evaluated. The study was created with a qualitative method.

Keywords: Smart City, Smart City Technologies, Internet of Things (IoT), Opportunity, Threat

Babahanoğlu, V., Bilici, Z. ve Örselli, E. (2020). “Teknolojik Devinimin Kentlere Getirmiş Olduğu Fırsat ve Tehditler: IoT Tabanlı Akıllı Kentler Üzerinden Bir Analiz", Journal of Academic Value Studies, 6(3) 254-265 (http://dx.doi.org/10.29228/javs.45352).

\footnotetext{
*Email address: erhanorselliorselli@gmail.com (Corresponding author)

** Bu çalışma 16-18.10.2019 tarihlerinde Kent Araştırmaları Enstitüsü tarafından düzenlenen IV. Uluslararası Kent Araştırmaları Kongresi’nde sunulan bildirinin gözden geçirilmiş ve genişletilmiş halidir.
} 


\section{Giriş}

Bilgi ve iletişim teknolojilerindeki gelişmeler öyle bir noktaya gelmiştir ki, tüm yaşamımızı derinden etkilediği gibi, teknolojinin sunduğu fırsatlar ile birlikte nesneler birbiriyle etkileşimde bulunarak yeni formlar kazanmaya başlamışlardır. Günümüzde aklımıza gelebilecek neredeyse her türlü nesne internet ile buluşarak adeta insanlarla iletişim kurma yeteneği kazanmıştır. Nitekim nesnelerin, internet ve sensörler aracilığıyla birbiri ile iletişim halinde olması onları bir bakıma akıllı nesnelere dönüştürmüştür. Bilişim teknolojileri ile bu tür teknolojilerin ortaya çıkması insanların yaşam alanlarını önemli ölçüde etkilemektedir. Yaşanan bu gelişmeler birtakım fırsatlar sağlamasının yanında birtakım tehditlere de neden olması söz konusudur.

Kentsel nüfusun her geçen gün katlanarak artması ve bununla birlikte kentlerin mega yerleşim yerleri haline gelmesi, çeşitli kentsel sorunların doğmasına ve büyümesine neden olmaktadır. Nitekim kentler de tıpkı insanlar gibi dinamik bir yapıya sahip olmalarından dolayı ortaya çıkan kentsel sorunlar zamana ve mekâna göre değişmekte ve gün geçtikçe karmaşıklaşmaktadır. Hızlı nüfus artışı, artan hava kirliliği, iklimlerin değişmesi, istihdam talepleri, enerji taleplerinin karşılanmasında kaynakların yetersizliği, yetersiz kalan alt yapılar, kent sakinlerinin artan oranda yenilikçi kentsel hizmet talepleri günümüzde kentlerin karşı karşıya kaldıkları başlıca sorunlar arasında sayılabilir. Birçok gelişmiş ülkede kentlerin karşı karşıya kaldığı sorunları yönetebilmeleri için geleneksel yöntemlerden vazgeçilerek, teknoloji ile bütünleşmiş çözüm yöntemleri tercih edilmeye başlanmıştır. Bu doğrultuda yaşanan teknolojik devinim ile birlikte kent ve insan yaşamı internet altyapısı ile donatılarak ayrıca nesnelere sensörler ve internet eklemlenerek akıllı kent konsepti hayata geçirilmiştir.

Teknolojinin kent yaşamına adapte edilmesi neticesinde ortaya çıkan ve akıllı kent konsepti bünyesinde sayılabilecek "akıllı evler, akıllı arabalar, akıllı ulaşım, akıllı sağlık ve akıllı yönetişim” gibi karşımıza çıkan birçok akıllı uygulama kentler ve kent sakinleri açısından birtakım kolaylıklar ile yeni "fırsatlar" sunduğu gibi, birtakım "tehditleri" de bünyesinde barındırmaktadır. Kentsel kaynakların daha verimli ve etkin kullanılması, trafik yoğunluğunun yönetilebilmesi, acil durum uyarı sistemleri, enerji tasarrufu, akıllı alt yapı sistemleri, zaman tasarrufu, çevre dostu ve insan merkezli kentsel hizmetlerin kent sakinlerine sunulması bu firsatların başında gelmektedir. Ancak bu olumlu yanlarının yanında, akıllı sistemlerin kurulabilmesi için ihtiyaç duyulan büyük bütçeler, siber güvenliğin sağlanmasındaki riskler ile kent sakinlerinin bu akıllı uygulamaları kullanabilme yeteneklerinin yokluğu gibi birtakım olumsuzluklardan bahsedilebilir.

Çalışmanın amacı yaşanan teknolojik devinimin kentler üzerindeki olumlu ve olumsuz etkisini IoT tabanlı akıllı kentler üzerinden incelemektir. Bu kapsamda çalışmada öncelikle akıllı kent kavramı ve akıllı kent bileşenleri incelenmiş, ardından teknolojik gelişmelerin kentler üzerindeki etkisi fırsat ve tehditler bağlamında değerlendirilmeye çalışılmışır. Çalışma nitel bir yöntemle hazırlanmış ve teknolojinin kentler üzerinde hem olumlu hem de olumsuz etkilerinin olduğu sonucuna ulaşılmıştır.

\section{Akıllı Kentler ve Bileşenleri}

Günümüzde kentler birbiriyle rekabet halinde olduklarından rakiplerinden farklılaştıkları ölçüde başarılı olarak görülmektedirler. Bunu sağlamanın yolu kentlerin teknolojinin imkanlarını kullanarak yapısal bir dönüşüm geçirmelerinden geçmektedir (Kılınç, 2019: 1101). Kentleşmenin ve bu sürecin oluşturduğu olumsuzlukların üstesinden gelebilmek ve etkili çözümler bulabilmek adına bilgi ve iletişim teknolojilerinin insanoğlunun kullanımına sunduğu olanakların kent yaşamına entegre edilmesi ile birlikte kentlerin dijitalleşmesi veya "akıllı" hale gelmesi söz konusu olmuştur. Nitekim "akıllı kent" kavramı teknolojinin yardımıyla kentsel sorunların üstesinden gelme ve kent sakinlerinin yaşamını kolaylaştırma düşüncesinin bir ürünü olarak ortaya çıkmış ve popülarite kazanmıştır. Literatürde birbirine yakın bazı tanımların olduğu görülmekle birlikte, henüz üzerinde uzlaşılmış bir akıllı kent tanımı bulunmamakta ancak mevcut tanımların özellikle kavramın bileşenlerinden yola çıkılarak yapıldığı söylenebilir.

Akıllı kent tanımları incelendiğinde genellikle tanımlarda teknoloji boyutuna (Şahin ve Yılmaz, 2019: 2900) vurgu yapılmakla birlikte, akıllı kentlerin diğer özelliklerine önem verilmemektedir. Nitekim akıllı kenti "insanı ve kentsel uyumu geliştirmek için bilgi ve iletişim teknolojilerini kullanan bir kent” (Kaya Altay ve Gökgür, 2019: 116) olarak tanımlamak ifade edildiği gibi eksik bir tanım olmaktadır. Çünkü akıllı kent yaklaşımı, teknolojinin kentsel yaşama adapte edilmesinin ötesinde bir süreç olduğu gibi öyle de ele alınmalıdır. Akıllı kentleri; bir kentin sakinleri için sürdürülebilir, müreffeh ve tüm paydaşlarını kapsayıcı şekilde geleceğe hazırlamak adına fiziksel altyapı araçlarını bilgi iletişim teknolojileri ile geliştirerek, 
kent sakinlerinin benimsemesi ile ortaya çıkan yenilikçi ve teknolojik yaklaşım (Örselli ve Dinçer, 2019: 93) olarak tanımlamak daha doğru olacaktır. Bu kapsamda akıllı kent yaklaşımının temel amacını, kamu kaynaklarının daha iyi kullanılması, vatandaşlara sunulan hizmetlerin kalitesinin artırılması ve hizmet maliyetlerinin düşürülmesi olarak sıralamak mümkündür (Zanella vd., 2014: 22).

Akıllı kentler, nesnelerin interneti, bulut bilişim, büyük veri ve coğrafi bilgi sistemleri gibi yeni nesil bilgi teknolojilerini uygulayan yeni bir konsept ve yeni bir kent modeli olarak kabul edilmektedir. Bu yönüyle akıllı kentlerin var olabilmesi, gelişimini ve sürdürülebilirliğini devam ettirebilmesi için birçok unsuru kapsaması gereklidir. Bu nedenle, akıllı kentlerin sürdürülebilir ve etkin olabilmesi kamusal hizmetlerin kolaylığı, akıllı altyapılar ve ağ güvenliğinin sağlanması gibi unsurları amaç edinmesi ile doğrudan ilintilidir (ISO/IEC, 2015: 2).

Geleneksel, bölgesel ve neoklasik kentsel büyüme ve kalkınma teorilerinin ardından akıllı kentler 6 bileşen etrafında tanımlanmıştır. Akıllı kentlere dönüşüm sürecinin planlanması ve bu dönüşüm sürecinin izlenmesi ile ilgili literatürde ve uygulamada çeşitli yaklaşımlar bulunmaktadır. Bu yaklaşımlardan, Cohen'in "Akıllı Kentler Çarkı (Smart Cities WheelSCW)" metodolojisi ön plana çıkmaktadır. Avrupa Birliği (AB) tarafından da kabul edilen bu yaklaşıma göre, akıllı şehirler 6 ana bileşenden oluşmaktadır (Zygiaris, 2013: 217; Elvan, 2017: 7; Bilici ve Babahanoğlu, 2018: 137).

Akıllı Çevre: Akıllı kent kavramının özünü, sürdürülebilirliği artırmak ve doğal kaynakları daha iyi yönetmek için teknolojinin kullanılması oluşturmaktadır. Doğal kaynaklar ile parklar vb. yeşil alanların korunması ve kanalizasyon gibi ilgili altyapıların yeterli düzeyde kurulmuş olması gibi faktörler özellikle sürdürülebilir bir çevre için önemlidir. Bu faktörlerin bir kentin sürdürülebilirliği ve yaşanabilirliği üzerinde yadsınamaz bir etkisi bulunmaktadır. Bu nedenle akıllı kentler incelerken bu tür çevresel faktörlerin önemi büyüktür (Chourabi vd., 2012: 2294). Bu bileşen, akıllı atık yönetimi, akıllı sensörler ile kirlilik kontrolü gibi çevrenin korunması ve denetlenmesi için bilgi ve iletişim teknolojilerinin kullanılmasını kapsamaktadır (Das, Sharma ve Ratha, 2019: 3). Akıllı çevre bileşeninin hayata geçirilebilmesi için enerji tüketimi neticesinde ortaya çıkan sera gazı emisyon yoğunluğu ile kent sakinlerinin maruz kaldığı hava kirliliği gibi verilerin nesnelerin interneti ile anlık takip edilerek gerekli analizlerin yapılarak gerekli önlemlerin alınması, sürdürülebilirlik çerçevesinde yeşil binalar ile yenilenen yapıların oranının artırılması, enerji yönetimi ve atık yönetimine ilişkin desteklerin olması ayrıca bu konudaki politikaların yürürlüğe konulması oldukça önemlidir (Erdoğan, 2019: 13).

Akıllı Ekonomi: Ekonomi, akıllı kentlerin en büyük itici gücüdür ve ekonomik rekabet edebilirliğe sahip olan kentlerin akıllı kent vasfını taşıdığından bahsetmek mümkündür (Chourabi vd., 2012: 2293). Bu nedenle akıllı ekonomi, yenilikçilik, girişimcilik, ticari markalar, iş gücü piyasasının üretkenliği ve esnekliği ile ulusal ve uluslararası pazarlara entegrasyon gibi ekonomik rekabet unsurlarını içermektedir (Balakrishna, 2012: 224). Nitekim bu bileşen ekonomik büyümeyi, istihdamı ve kentsel refahı artıran teknolojik yaklaşımlar olarak kabul edilmektedir (Das, Sharma ve Ratha, 2019: 3). Bununla birlikte kentsel ekonomiler daha önce görülmemiş bir şekilde büyürken, gelişmekte olan ülkelerdeki işşilerin önemli bir kısmı kayıt dışı istihdam edilmektedir. Ayrıca yetişmiş vasıflı iş̧̧ilerin yeterli düzeyde olmayışı, kent ekonomilerinin büyümesinin önünde duran ciddi sorunlardandır (Kumar ve Dahiya, 2017: 6).

Akıllı İnsan: Akıllı kentlerin önemli bileşenlerinden biri de insandır. Akıllı kent yaklaşımının tek hedefi sadece kentlerin akıllı hale getirilmesi olmadığı gibi kent sakinlerinin daha akıllı hale gelmesidir. Çünkü akıllı kent uygulamalarını kullanacak ve bu uygulamalardan yararlanacak olanlar kentlerde yaşayanladır. Bir başka ifadeyle insanlar yeni teknolojileri verimli bir şekilde kullanabilir olmalıdır. Bu bakımdan kentlerin akıllı ekonomik ve sosyal gelişimini desteklemek için akıllı entelektüel sermayenin varlığı önem arz etmektedir (Dameri, 2013: 2547). Akıllı insan bileşeni sadece vatandaşların yeterlilik düzeyi ya da eğitim düzeyleriyle ile ilgili değil aynı zamanda kamusal yaşam ve "dış" dünyaya açılması ile ilgili entegrasyon ve sosyal etkileşimlerin kalitesi olarak da tanımlanmaktadır (Balakrishna, 2012: 224). Akıllı insan faktörü, yaşam boyu öğrenmeye yakınlık, sosyal ve etnik çoğulculuk, esneklik, kozmopolitlik, açık fikirlilik ve kamusal yaşama katılım gibi çeşitli unsurları içermektedir. Ayrıca kentsel yığılmalar ile ilgili sorunlar beşerî sermaye ve ilgili paydaşlar arasındaki iş birliği ile çözülebilir. Bu nedenle, "akıllı kent” kavramı, akıllı insanların kentsel sorunlara akıllı çözümler üretme kapasitesini ifade etmelidir (Albino, Berardi ve Dangelico, 2015: 11). Bu perspektiften bakıldığında akıllı kentlerin tüm bileşenlerinin içerisinde akıllı insan bileşeninin önemli bir yer tuttuğu söylenebilir. Nitekim, akıllı insan bileşeni sağlanamazsa diğer bileşenlerin tümünün varlığından faydalanabilecek bir unsur bulunamayacağını söylemek yerinde olacaktır. 
Akıllı Yönetişim: Akıllı yönetişim akıllı kentlerin çekirdeği olarak kabul edilmektedir (Paskaleva vd., 2017: 4). Akıllı yönetişim; dil, kültür, eğitim vb. alanlarla ilgili engellerin kaldırılmasını gerektirmektedir (Albino, Berardi ve Dangelico, 2015: 11). Akıllı yönetişim, kentsel sorunları sürdürülebilirlik ilkesi bağlamında ele alıp teknoloji yardımıyla çözüme kavuşturabilmek adına, kent yönetimi ile vatandaşlar arasında yeni iş birliği yoluyla bir araya getiren bir yaklaşım olarak görülmektedir. Akıllı yönetişimin üç yapı taşından söz edilebilir. Akıllı yönetişimin ilk yapı taşı devletin örgütlenme biçimidir. İkinci yapı taşı vatandaş katılımıdır. Son yapı taşı ise teknolojinin, özellikle bilgi ve iletişim teknolojilerinin kullanılmasıdır (Tomor, Meijer, Michels ve Geertman, 2019: 3-10). Akıllı yönetişim politik katılımın yanı sıra vatandaşların yönetsel süreçlere de katılmasını içermektedir (Balakrishna, 2012: 224). Bu bileşen kapsamında e-devlet, sosyal medya ve sivil toplum kuruluşları aracılığıyla karar verme süreçlerine mümkün olduğunca kentin tüm paydaşlarının dâhil edilmesi söz konusudur (Letaifa, 2015: 1416). Bir başka ifadeyle akıllı yönetişim unsuru ile akıllı kentlerde sağlanmak istenen, kent sakinlerinin doğrudan kendilerini temsil etmesi için arzularını ve yeterliliklerini kullanmaları ve bunların koordine edilmesidir (Örselli, Bayrakcı ve Göksoy, 2019: 236).

Akıllı Yaşam: Akıllı kentler yaşayan bireylerin eğitimleriyle beraber mesleki yetenekleri ve kültürel seviyeleri, sosyal ilişkileri ve sosyal sermayeleri ve sivil toplum örgütlenmeleri kentsel yaşam kalitesini etkilemektedir (Dameri, Benevolo, Veglianti ve Li, 2019: 6). Bir başka ifadeyle akıllı yaşam; sağlık, güvenlik, barınma, sağlıklı çevre, sosyal uyum, kültürel ve eğitim hizmetlerinin kullanılabilirliği açısından ölçülen yaşam kalitesinin çeşitli yönlerini içermektedir (Buhalis ve Amaranggana, 2014: 556). Zira kentlerde yaşayanlar; aynı zamanda eğitimlerine kentlerde devam ederler ve kentlerde çalışıllar, ya da bazı kültürel ve eğlence mekanlarında zaman geçirirler (Dameri, 2014). Bu bağlamda akıllı yaşam insanların tamamen dijitalleşmeye boğulup sınırlı olarak sosyalleştikleri bir yaşam anlamına gelmemektedir.

Akıllı Hareketlilik/Ulaşım: Hareketlilik günümüz modern yaşamının önemli bir yönünü oluşturmaktadır. İnsanların ve malların kent içerisinde yer değiştirmesi günlük yaşam için hayati öneme sahiptir. Bu nedenle hareketlilik kavramı sadece ulaşım veya trafik odaklı düşünülmemelidir (Aletà, Alonso ve Ruiz, 2017: 165). Akıllı hareketlilik modern ulaşım sistemlerinin kent içinde ve dışında erişilebilirliğini ve kullanılabilirliğini ifade etmektedir (Buhalis ve Amaranggana, 2014: 556). Akıllı hareketlilik, trafik akışının optimizasyonunu desteklemek için kullanılan aynı zamanda vatandaşların kentlerde daha rahat yaşayabilmesi ve hareket edebilmesi ile yerel toplu taşıma hizmetlerinin kalitesi hakkındaki görüşlerinin toplandığı bilgi ve iletişim teknolojileri yoluyla planlanması (Benevolo, Dameri ve D’Auria, 2016: 13) olarak görülebilir. Akıllı ulaşım uygulamaları arasında trafik akışını yönlendirme, akıllı kavşak, akıllı park, akıllı durak, GPS takibi, yolcu bilgilendirme gibi birçok hizmet sayılabilir (Varol, 2017: 54).

\section{Akıllı Kentler İçin IoT Teknolojisi ve Uygulama Alanları}

Akıllı kent vizyonu genel olarak bilgi ve iletişim teknolojilerinin tam olarak kent yaşamına entegre edilmesine ve veri analitiğine dayanmaktadır. Bununla birlikte, akıllı kent için gerekli olan tek bileşenin teknoloji olmadığı ifade edilmişti. Gerçek manada bir akıllı kent aynı zamanda toplumdaki sosyal yatırımlara, çevre sorunlarına, sosyal davranışlara ve vatandaş katılımına göre vatandaş davranışını değiştirmeye dayanmaktadır (Löfgren ve Webster, 2020: 2).

Teknolojide yaşanan dönüşüme rağmen karar verme, analitik düşünme, sorun çözme gibi görevler her zaman insanoğlunun kontrolünde olmuş ve gözetiminde yürütülmüştür. Ancak teknolojide yaşanan gelişmelerle birlikte, insanın karar verme görevini ikame edecek bir teknolojik yapının doğması söz konusu olmuştur (Akçomak, 2018: 67). Bir başka ifadeyle başta ulaştırma ve enerji olmak üzere, çeşitli kentsel altyapılar ve şebekeler insan müdahalesine gerek kalmadan kendi kendini yönetebilme yeteneği kazanmaya başlamışlardır. Böylece, akıllı kent uygulamaları ile insanların yaşam standartlarında önemli düzeyde bir iyileşme gerçekleştirilmesi hedeflenmektedir (Elvan, 2017: 7).

İnternete bağlanabilen cihazların kullanımının yaygınlaşması neticesinde nesnelerin interneti (IoT-Internet of Things), kamu yönetimleri açısından da önemli hale gelmiştir. Merkezi ve yerel yönetim birimleri daha etkin ve etkili hizmet sunumu sağlamak, yaşanabilir ve yönetilebilir bir kent ortamını hayata geçirmek amacıyla sensörler, kablolu ve kablosuz iletişim teknolojilerini, gelişmiş ağ ve GPS sistemlerini IoT kapsamında kullanmaya başlamışlardır (Göçoğlu, 2020: 625). $\mathrm{Bu}$ kapsamda özellikle yerel yönetimler akıllı kent mimarisini tasarlarken yoğun bir biçimde IoT teknolojisinden yararlanmaktadırlar. Bu bağlamda IoT tabanlı akıllı kentlerin sunmuş olduğu firsat ve tehditleri analiz edebilmek için öncelikle IoT teknolojisini ve bu teknolojiyi meydana getiren diğer teknolojileri ele alıp incelemek yararlı olacaktır. 
IoT kavramının ilk kullanımı dijital inovasyon uzmanı Ashton'a atfedilmesine rağmen farklı yazarlar tarafından yapılan birçok tanımdan bahsedilebilir. Tanımlar incelendiğinde ortak noktanın, internetin ilk versiyonunun insanlar tarafından oluşturulan verilerle ilgili olduğu, bir sonraki versiyonun ise nesneler tarafından oluşturulan verilerle ilgili olduğu fikridir. Bu bakımdan IoT kavramı için, otomatik organize etme, bilgi, veri ve kaynakları paylaşma, ortamdaki durumlara, değişikliklere karşı tepki verme ile hareket etme kapasitesine sahip açık ve kapsamlı akıllı nesneler ağı tanımlamasının yapılması yerinde olacaktır (Madakam, Ramaswamy ve Tripathi, 2015: 165).

IoT kapsamında geliştirilen uygulamalar kullanıc katılımı ve etkisi, ağ erişilebilirliği, kapsama alanı, ölçeklenebilirlik, heterojenite ile tekrarlanabilirlik türlerine göre sınıflandırlabilmektedir. IoT, bu uygulamaların organizasyon yapısı arasındaki bilgi akışını geliştiren önemli bir teknoloji olarak kabul edilmektedir. Aşağıda Şekil 1'de IoT uygulama alanları ve onlara bağlı bazı senaryolar gösterilmektedir (Khalil ve Özdemir, 2018: 317).

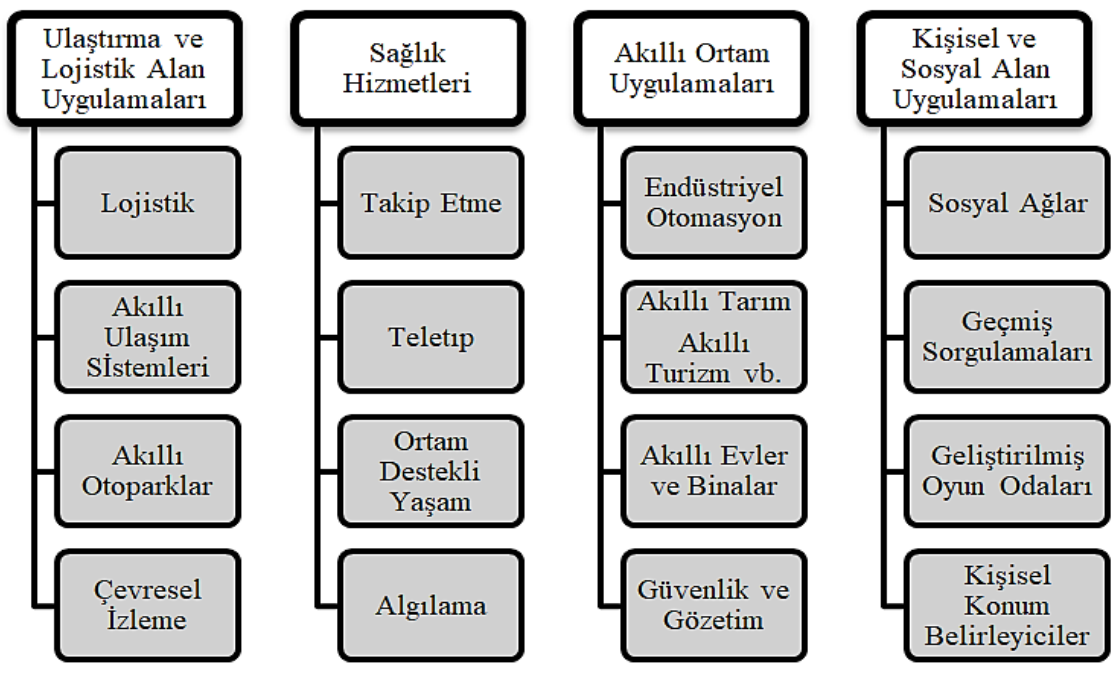

Şekil 1. IoT Uygulama Alanları ve Senaryoları

Kaynak: Khalil ve Özdemir, 2018: 318'den uyarlanmıştır.

Akıllı kentlerin oluşum sürecinde en önemli unsur IoT teknolojisi ve bu teknolojinin kullanılabilmesidir. Çünkü kentsel mekânlarda yaşanan sorunların ve aksayan hizmetlerin cihazlar, sensörler, network altyapıları, bulut sistemleri ve çeşitli yazılımlar geliştirilerek çözülmesi hedeflenmektedir (Terzi ve Ocakçı, 2017: 12-13). IoT, nesnelerin küçük boyutlu cihazlarla buluta bağlanması, iletilmesi ve depolanması için ölçek ve platform sağlamaktadır (Verma vd., 2019: 6). Uzun bir süre, "ZigBee" ve "Bluetooth" gibi çok kanallı kısa mesafeli iletim teknolojileri, IoT servislerini uygulamak için en uygun yol olarak kabul edilmiştir. Her ne kadar bu standartlar birçok IoT cihazı için temel bir gereklilik olan çok düşük güç tüketimi ile karakterize edilse de sınırlı kapsamları, özellikle uygulama senaryosu kent çapında kapsama alanı gerektiren hizmetleri içerdiğinde büyük bir engel olarak ortaya çıkmışlardır. Bazı akıllı kent hizmetlerinin denenmesi gerçekten de bu tür IoT uygulamaları için çok hatlı kısa menzilli uygulamaların sınırlarını ortaya koymuştur (Centenaro, Vangelista, Zanella ve Zorzi 2016: 60).

IoT ile verilerin algılanması ve işlenmesi dâhil olmak üzere iki görev gerçekleştirilir, ancak bunlar kablosuz sensör ağı (WSN) kullanılarak birleştirilememektedir. Bu bakımdan birleşik çözümler Speakthing ve iOBridge uygulamaları tarafından sağlanmaktadır. Speakthing, buluttaki canlı verileri toplamak, görselleştirmek ve analiz etmek için bir IoT platformu olarak tanımlanmaktadır. Elde edilen veriler ise MATLAB kodlaması ile analiz edilebilmektedir. Bunun aksine, iOBridge'in buluta bağlı olan ve web ara yüzleri üzerinden erişilebilen ve toplanan veriler diğer web servisleriyle birleştirilebilen kendi donanım modülleri vardır. Akıllı kentlerde bulutun veri depolama ve işleme için çok önemli olduğu dikkat çekicidir (Choudhary, Sathe ve Kachare, 2017: 435).

IoT geniş bir stratejidir ve tam teşekküllü dağıtım için dünyanın her yerinde varlığı gerekmektedir. Dolayısıyla böyle bir teknoloji geniş çapta kabul gören ve etkili bir çalışma ortamının varlı̆̆ına ihtiyaç duymaktadır. İnternet başlangıçta kablolu iletişim yoluyla yaygınlaştığı için IoT'in kablolu iletişimde de uygulanabileceği söylenebilir. Ancak kablolu ağın mobilite sorunları ve kurulum maliyeti göz önüne alındığında kendi dezavantajları bulunduğundan kablolu iletişim her yerde 
gerçekleştirilemez (Suresh, Daniel, Parthasarathy ve Aswathy, 2014: 2). IoT kullanılmasında, milyonlarca sensörün kablolama maliyetleri pratik olmadığı ve çok pahalı olduğu için sensörler arasındaki iletişim kablosuz olması gerekmektedir. $\mathrm{Bu}$ yüzden düşük güçlü standart iletişim, birçok cihaz arasında ara bağlantı için uygundur. Özellikle, konuma ve gerekli kapsama alanına bağlı olarak, akıllı kentlerde farklı ağ yapıları bulunmaktadır (Hancke, Silva ve Hancke, 2012: 396).

\section{Fırsat ve Tehditler Bağlamında IoT Tabanlı Akıllı Kentler}

IoT akıllı kentler bağlamında tüm kentsel mekanları otomatikleştirmek ve her şeyi internet üzerinden yönetmek anlamına gelmektedir. Kentlerde trafik akışını kontrol etmekten çevrenin kirlilik seviyesini izlemeye kadar çok çeşitli akıllı uygulamalar IoT ile mümkün hale gelmektedir. Ayrıca akıllı parklar, binalarda sismik titreşimleri (depremi önceden belirleyebilmek) izlemek, trafik akışını düzenlemek ve yönetmek, akıllı kavşaklar, atık yönetimi, tedarik zinciri yönetimi gibi uygulamalar da sayılabilir (Suresh, Daniel, Parthasarathy ve Aswathy,, 2014: 6). Bu sayılan akıllı uygulamaların gerçekleştirilebilmesi için sensörlerin hayati rolleri bulunmaktadır. Başka bir ifadeyle geleceğin akıllı kentlerinde, günlük olarak kullanılan hemen hemen her araca, cihaza ya da ekipmana bağlı sensörler ile IoT sistemlerinin yaşam alanlarında ve iş çevrelerinde devrim yapmasını sağlayacaktır (Das, Sharma ve Ratha, 2019: 8). Son zamanlarda insanlar artık yavaş yavaş evlerini birçok IoT cihazıyla donatırken, akıllı kentlerde bu uygulamalardan son derece etkin faydalanabilmektedir. Örneğin; ulaşım araçlarına yerleştirilen sensörler sayesinde güvenlik birimlerine ve itfaiyeye ait araçlar, belediyelerin çöp toplama araçları ile ambulanslar eskiye nazaran çok daha hızlı ve güvenli bir biçimde takip edilerek yönlendirilebilmektedir (Yıldız, 2019: 254). Akıllı kentler IoT teknolojisi ile donatılarak güvenlik, sağlık, barınma, enerji, çevre, ekonomi gibi alanlardan toplumsal entegrasyona varıncaya kadar birçok alanı etkisi altına almaktadır. Bir bütünün parçaları olarak iç içe geçmiş kompleks bir yapıyı ortaya koyan IoT tabanlı akıllı kentlerin etki alanları aşağıda Şekil 2'de gösterilmektedir.

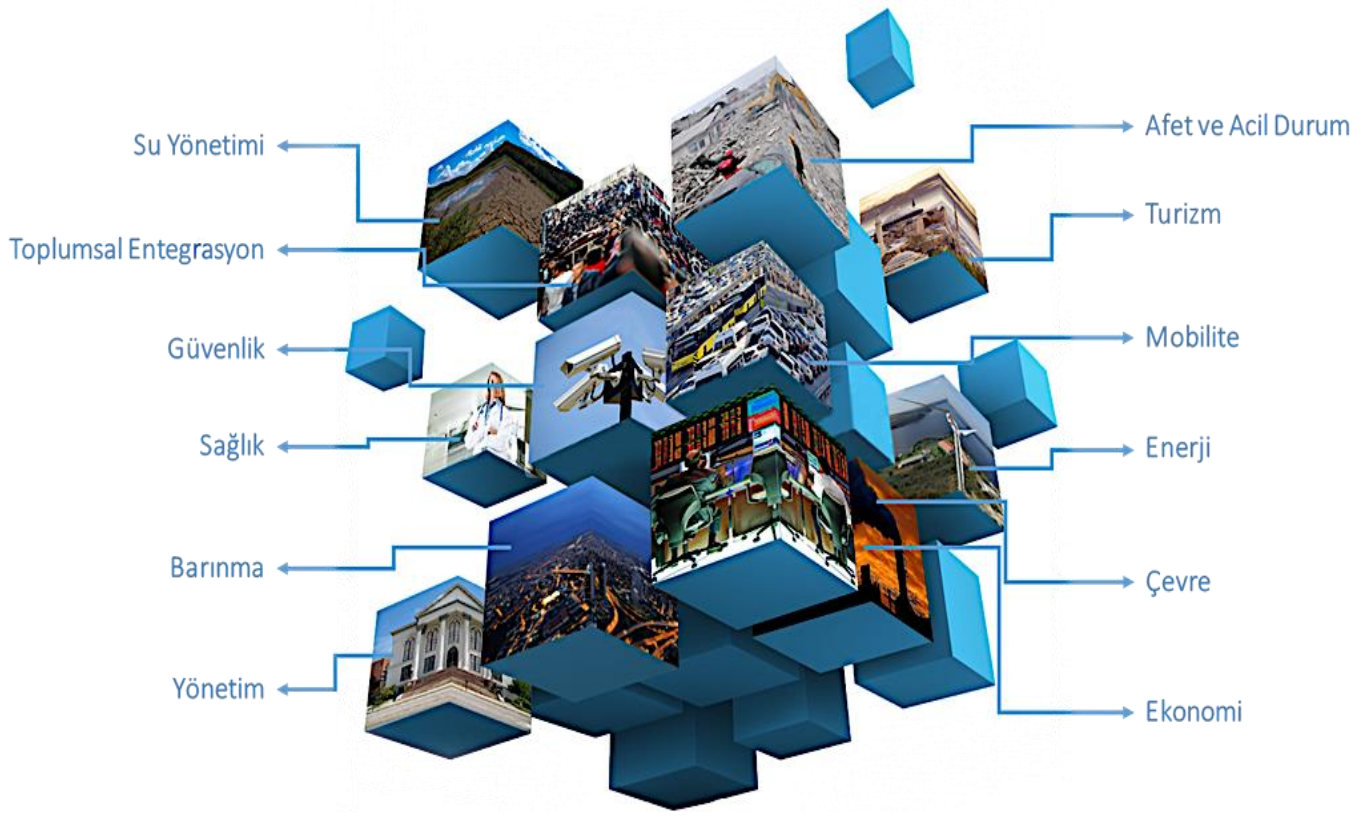

Şekil 2. IoT Tabanlı Akıllı Kent Etki Alanı

Kaynak: Etüd Bilişim, 2018

2016 yılında Paris'te düzenlenen Birleşmiş Milletler İklim Değişikliği Konferansında (COP21), birbiriyle bağlantılı nesneler yoğun bir şekilde ele alınmış ve birçok devlete IoT kullanımıyla karbondioksit (CO2) emisyonlarını azaltmak için fırsatlar sağladığını göstermiş ve böylece ülkelere çevresel hedeflerini yeniden düşünme fırsatı vermiştir. Nitekim akıllı atık uygulamaları buna verilebilecek en güzel örneklerdendir. Akıllı çöp konteynırları sayesinde çöp toplama hizmetlerinin daha sağlıklı ve zamanında yapılabilmesi mümkün hale gelecektir (Hammi vd., 2018: 1). Atık yönetiminde, kamyon güzergahı akıllı atık konteynerleri tarafından yük seviyesi göstergesine göre optimize edilerek atık toplama maliyetini azaltabilir, böylece geri dönüşüm kalitesini artır1labilir (Mehmood vd., 2017: 18).

IoT kentlerde yalnızca insanların yaşam kalitesini artırmak için değil, aynı zamanda maliyetleri azaltma konusunda akıllı aydınlatma, atık ve su yönetimi gibi birçok hizmet alanında çok çeşitli fırsatlar sunmaktadır. Örneğin, akıllı IoT 
modülleri, enerjiyi verimli bir şekilde dağıtmak ve tüketmek için şebeke istasyonları, evler ve işyerleri içine yerleştirilebilmektedir. E-sağlık hizmetlerinde, IoT cihazları, sıcaklık, nabız ve şeker seviyesi gibi sağılı parametrelerini izlemek için hastaların vücutlarına yerleştirerek, doktorların hastalarını düzenli olarak izlemeleri için firsatlar sunmaktadır. Hatta insanların sağlık problemlerini analiz ederek, hastalıkların teşhis edilmesini, acil durumlarda yetkililere haber verilmesini ve günlük sağlık istatistiklerine göre uyarılar verilmesini mümkün kılmaktadır (Rajab ve Cinkelr, 2018: 1).

Akıllı kentler, akıllı otopark, akıllı sağlık, kentsel gürültü haritalaması, trafik yoğunluğu izleme ve rota optimizasyonu ile akıllı sokak aydınlatması için gerekenler dâhil olmak üzere çeşitli IoT sensörlerini barındırmalıdırlar. IoT, akıllı kent bileşenleri için olanak sağlayan bir teknoloji olarak kabul edilirken, bulut sistemleri ise merkezi veri depolama ve görüntülemeye olanak sağlayan platform olarak kabul edilmektedir (Baig vd., 2017: 1).

Bilgi ve iletişim teknolojisi söz konusu olduğunda güvenlik her zaman önemli olmuştur. Bulut hizmetleriyle, internet üzerinden herhangi bir yerden erişilebilen kritik verilerin ele alınması, güvenliği önemli bir sorun haline getirmektedir. Bulut sistemlerinin yaygın yapısı ve çeşitli coğrafi konumlarda verinin dağıtılması yüksek güvenlik riskleri anlamına gelmektedir. Bulut güvenliğinden söz ederken, güvenilir kimlik doğrulama, uygun yetkilendirme, veri güvenliği ve gizlilik gibi dikkate alınması gereken birçok husus söz konusudur. Bunlar, her bulut sağlayıcısının dâhil etmesi için son derece önemli olan temel güvenlik hedeflerinden sadece bazılarıdır. Güvenlik, bilgi ve iletişim teknolojisi için bir özellik olarak görüldüğü için, veri şifreleme, veri güvenliği korumasını sağlamada kilit önlemlerden biri olarak kabul edilmektedir (Arora, Khanna, Rastogi ve Agarwal, 2017: 288).

Her IoT cihazı için güvenlik bir zorunluluktur. Akıllı kentler çok çeşitli cihazlara İnternet bağlantısı sağladığından, güvenlik çok önemli hale gelir. Güvenlik açıkları çeşitli risklere neden olacağı için başarılı bir IoT tabanlı akıllı kent tasarlayabilmek için, aşağıda belirtilen hususlara dikkat edilmelidir (Mehmood vd., 2017: 21):

- Kullanıı verileri için gizliliğe duyarlı iletişim sağlanmalıdır.

- Veri doğruluğunu ve bütünlüğünü sağlamak ve IoT cihazları ile bulut tabanlı bir uygulama merkezi arasında güvenli iletişim sağlamak için basit, hafif ve verimli güvenlik çözümleri tasarlanmalıdır.

- Güvenlik açıkları ve tehditler bağlamında ortaya çıkması muhtemel yeni saldırıları tespit etmek için ayrıntılı risk değerlendirmesi yapılmalıdır.

- $\quad$ Etkin ve yeterli bir güvenlik yönetim sistemi tasarlanmalıdır.

- Kullanıcıların sisteme güvenleri ciddi gizlilik tedbirleri alınarak sağlanmalıdır.

Akıllı kentler, vatandaşlarının yaşam kalitesini yükseltmek için çeşitli yenilikçi ve ileri hizmetlerin sunumuna aracılık etmektedir. Akıllı bir kent, özü IoT olan son derece gelişmiş ve entegre teknolojiyi kapsamaktadır. Akıllı yönetişim, akıllı iletişim, akıllı çevre, akıllı ulaşım, akıllı enerji, atık ve su yönetimi uygulamaları gibi akıllı teknolojiler kentlerin akıllı büyümesini vaat etmektedir. Ancak akıllı kentler aynı zamanda, bu akıllı uygulamalar ile ilişkili geniş hacimli verilerin güvenliği ve gizliliğini de sağlaması gerekmektedir. Ayrıca akıllı kentler, kentsel aktarımın yenilikçi yönetimindeki kentleşme eğilimlerini ve sürekli artan talepleri karşılamak amacıyla bölge sakinlerine, ziyaretçilere ve yerel yönetime çeşitli akıllı hizmetler sağlamak için özel akıllı önlemler alması gerekmektedir. Kent sakinleri akıllı kent uygulamalarının güvenlik açıkları nedeniyle çeşitli gizlilik ve güvenlik sorunları karşısında birtakım zararlarla karşı karşıya kalabilirler (Verma vd., 2019: 1). Akıllı kent projelerinin güvenlik ve gizlilik tehditleri, açıkları ve zorlukları aşağıda Tablo 1'de gösterilmektedir.

Tablo 1. Akıllı Kentlerde Güvenlik ile Gizliliğge İlişkin Zorluk ve Tehditler

\begin{tabular}{|c|c|c|}
\hline $\begin{array}{c}\text { Akıllı Kent Güvenliğine } \\
\text { Yönelik Zorluklar }\end{array}$ & $\begin{array}{c}\text { Yönetişim Güvenliğine } \\
\text { Yönelik Endişeler }\end{array}$ & $\begin{array}{c}\text { Gizlilikle İlgili } \\
\text { Sorunlar }\end{array}$ \\
\hline $\begin{array}{c}\text { Çeşitli Uygulamalar ile } \\
\text { Bilgiye Erişim }\end{array}$ & $\begin{array}{c}\text { Güvenlik Testinin } \\
\text { Gerekliliği }\end{array}$ & Veri Türleri \\
\cline { 1 - 1 } Bilgi Takibi & $\begin{array}{c}\text { Akıllı Mobilite } \\
\text { Vatandaşların Takibi }\end{array}$ & Verinin Amacı \\
\cline { 1 - 1 } $\begin{array}{c}\text { Vatandaşlarının Verilerini } \\
\text { Kaybetmek }\end{array}$ & Güvenliğinin Gerekliliği & Kişisel Olmayan Veri \\
\cline { 3 - 4 }
\end{tabular}




\begin{tabular}{|c|c|c|}
\hline Veri Merkezlerinde Bilgiye & & Veri Algılamada Gizlilik \\
İzinsiz Erişim & \multirow{2}{*}{ Verimli Enerji Kullanımı } & Çıı̧ı \\
\cline { 1 - 1 } $\begin{array}{c}\text { İstemci Tarafında İzinsiz } \\
\text { Erişim }\end{array}$ & & Veri Depolama ve \\
& & İşlemede Erişilebilirlik ve \\
Gizlilik
\end{tabular}

Kaynak: Verma vd., 2019: 7-13'den uyarlanmıştır.

IoT tabanlı kurulan akıllı kentlerde IoT cihazlarına ve sensörlerine yönelik çeşitli tehditler söz konusu olabilmektedir. $\mathrm{Bu}$ kapsamda verilerin güvenliğini sağlamak için veriler ve bu verilerle ilgili çeşitli bilgiler farklı boyutlarda korunmak zorundadır. IoT cihazlarına ve sensörlerine yönelik gerçekleşebilecek bazı güvenlik ve gizlilik tehditleri aşağıda yer almaktadır:

- Gizlilik ve Bütünlük: Veri sahipleri, verilerini bulutta uzaktan depolayarak bu verilerini dış kaynaklardan alabilir ve paylaşılabilirler. Ancak, veri sahipleri ve bulut sunucuları aynı güvenilir etki alanında olmadığından dış kaynaklı veriler, bulut sunucusuna tam olarak güvenilemeyebileceğinden veri gizliliği ve bütünlüğü noktasında çeşitli riskler taşıyabilmektedir. Bu nedenle, böyle bir durumda veri gizliliği, kullanılabilirliği ve bütünlüğü çok önemlidir. Yetkisiz kişilerin erişim sağlaması durumunda cihaz ve sensör verilerinin bütünlüğü tehlikeye girebilir (Mukundan, Madria ve Linderman, 2014: 507; Baig vd., 2017: 5).

- Dinleme: Kablosuz Sensör Ağı (WSN); IoT altyapısı kapsamında çevre izleme, yapısal sağlık izleme, güvenlik, keşif ve erken uyarı uygulamaları gibi çeşitli uygulamalara hizmet edebilmektedir. Bu kapsamda sensör ve merkezi sunucu arasındaki iletişim güvenli değilse, verilerin bütünlüğü tehlikeye girebilir. Veriler merkezi sunucuya iletilirken, sensörlerin yanlış eylemleri iletmesine ve sunucuların yanlış olayları kaydetmesine neden olabilecek şekilde iletişim durdurulabilir ve değiştirilebilir. Bu tür bir faaliyetin amacı, belirli bir olay ya da olguyla ilişkili hassas verilere yasadışı yollardan erişmektir (Baig, 2014: 76; Baig vd., 2017: 5).

- Veri Kaybı: Dijital teknoloji, IoT verilerinin depolanmasını ölçeklendirmek için muazzam bir şekilde geliştirilmekle birlikte sensörlerin yetersiz veri yönetimi, akıllı bir kentin faaliyetlerini etkileyebilir. Veri yönetimi, akıllı kent ortamında sensörleri etkin ve güvenli bir şekilde kullanmak için dağıtım uygulamalarını, prosedürlerini ve politikalarını içermektedir. Veriler yeterince yönetilmezse sensörler ile toplanan, iletilen ve saklanan sensör verileri tehlikeye girebilir (Baig vd., 2017: 5; Mishra, Lin ve Chang, 2015: 1-5).

- Kullanılabilirlik Tehlikesi: Bulut servis sağlayıcısının sunduğu hizmetler, tüm sistemi yok edebilecek tek bir başarısızlık derecesi riski olan yüksek düzeyde bir risk içerir. Güvenlik, güvenilirlik ve kullanılabilirlik bulut bilişimin en önemli konusunu oluştururken, bugün bulut sistemleri bazı problemlerle karşı karşıyadır. Hassas verilerin güvenliği bir kurumun en büyük önceliğini oluşturmaktadır. Sensör arızası durumunda akıllı bir kentin operasyonlarını olumsuz etkilemekten kaçınmak için prosedürler ve planlar yapılmalıdır. Örneğin, trafik tıkanıklığı sensörleri ana yollarda yeşil ışıkları yanlış göstermesi durumunda, daha küçük olan yan yollarda trafiğin tıkanmasına ayrıca böyle bir sensör arızası trafiğin kilitlenmesine neden olabilir (Khan vd., 2016: 550; Baig vd., 2017: 5).

- Uzaktan Yararlanma: IoT sistemleri doğal olarak fiziksel sistemleri kontrol ettiğinden, kamu güvenliği doğal bir konudur. Kamu sektöründe bu, taşıma sistemleri, elektrik dağıtımı ve su arıtımının yanı sıra dağıtım ve depolama için de geçerlidir. IoT denetleyicilerinin dağınık doğası çoğu zaman modern güvenlik kontrollerini veya protokollerini desteklemeyen bileşenlerle birlikte kullanılan ortak senaryo, uzaktan erişimin ortak bir saldırı vektörü olduğu yönündedir. Akıllı bir kente bağlı sensörler merkezi bir sunucu ile iletişim kuracağından, uzaktan yararlanabilmek için güvensiz iletişim kanalları kullanılabilir (Cisco, 2015: 2-5; Baig vd., 2017: 5).

Özetle akıllı kentlerin tüm unsurları çevrimiçi olarak birbirleriyle veri alışverişinde bulunmaktadır. Akıllı sistemler tarafından oluşturulan kent ortamı veri hırsıları için oldukça ilgi çekici olabilmektedir. Bu tarz sistemleri kullanan kentler; akıllı bir kent oluşturmayı, kentin insanlarına ve tüm bölgelerine yayılarak kent yaşamını kolaylaştırmayı amaçlamaktadır. Bununla birlikte, trafik izleme sensörlerine veya kent işletim sistemine sızan bir veri hırsızının neden olabileceği kaotik koşulları göz önüne almak zorunludur. Önde gelen güvenlik araştırmacıları, akıllı kentler gibi açık, hassas veri alışverişlerinin bilgisayar korsanlarına ve bilgisayarlara göre daha savunmasız olabileceğini belirtmektedir. Güvenlik araştırma şirketi IO Active Labs, kentlerin sel ve deprem gibi doğal afetlere karşı planları olmasına rağmen, birçok kentin siber saldırılara karşı koyacak bir planlarının olmadığını belirterek akıllı kentleri yönetenleri uyarmaktadır. İnsan merkezli bir felaket büyük 
yıkımlara yol açabileceğinden, akıllı kentlere yönelik gerçekleştirilmesi muhtemel siber saldırılara karşı akıllı stratejiler geliştirilmelidir (Efe, Aksöz, Hanecioğlu ve Yalman, 2018: 37).

Çeşitli teknolojilerle donatılmış akıllı kentlerde yaşanan en büyük sorunlardan bir diğeri de çağımızın en büyük sorunları olarak kabul edilen gözetim toplumlarının oluşturulmasıdır. Akıllı kentlerde sokaklar, caddeler, binalar, ana yollar, ofis içleri gibi neredeyse kentin her noktasına çok sayıda ve çeşitli sensörler, kameralar ve gözetim araçları yerleştirilmektedir. $\mathrm{Bu}$ durum kentin neredeyse her alanında toplumun denetlenmesi, kayıt ve gözetim altına alınması ile yönlendirilmesi anlamına gelir ki, bu durum toplumda insanlar korku ve çekinceler yaşayarak aidiyet duygusunu yitirir. Bunun karşıllğında insanlar kendilerini yalnız ev ortamında özgür ve rahat hissedebilmektedir. Gözetim toplumlarında gerçek bir kamusal alanın varlığından ve demokrasinin varlığından söz edilmesi ise mümkün değildir (Çakır, 2019: 24).

IoT ile donatılmış bir akıllı kentte günümüz şartlarında gizlilik ve güvenliğin garanti altına alınması zor görülmektedir. İnsanların 7/24 izlenerek tüm hareketlerinin, sağlık verilerinin, günlük aktivitelerinin kayıt altına alınması; bilgi güvenliği, kişisel veriler ile özel hayatın gizliliği konularını gündemin üst sıralarına taşımaktadır. IoT teknolojisi ile elde edilen veri merkezlerine kötü niyetli kişiler tarafından gerçekleştirilen erişim sayesinde akıllı alarm ve kilit sistemlerinin devre dışı bırakılarak siber hırsızlıkların yaşanması, giyilebilir nesnelere sızılarak, vücut aktivitelerinden hastalıkların tespit edilmesi ve bu kapsamda siber cinayetlerin işlenmesi gibi örnekler IoT’nin güvenlik eksiklikleri olarak değerlendirilmektedir (Gündüz ve Daş, 2018: 334).

\section{Sonuç}

Teknolojinin, insan ve kent hayatına entegre edilmesi ile sürdürülebilir ve rekabetçi kent anlayışı hedeflenmiştir. Böylece kentler hem insan yaşantısı açısından daha pratik çözümler geliştirmekte hem de daha yönetilebilir bir hal almaktadırlar. "Akıllı" hale gelen kentler; toplumsal problemlerin çözümünde büyük bir potansiyele sahip olarak, ekonomik ve sosyal anlamda kentleri birer cazibe merkezi haline getirmektedir. Akıllı kentler, kent yaşamıyla ilintili, çevre ve yaşam alanlarındaki performansı bilgi iletişim teknolojileri vasıtasıyla ileriye taşımaya çalışan bir anlayışı ifade etmektedir.

Akıllı kent kavramının üzerinde uzlaşılmış bir tanımı olmamasına rağmen, nihai amaç kamu kaynaklarının daha iyi kullanılmasını sağlamak, vatandaşlara sunulan hizmetlerin kalitesini artırarak kamusal hizmetlerin sunum maliyetlerini azaltmak ve kentlilerin yaşam kalitesini iyileştirmektir. Bu amaç, kentsel bir IoT'in konuşlandırılmasıyla, yani kamu hizmetleri ile birleştirilmiş, basit ve ekonomik erişim sağlayan ve böylece potansiyel sinerjileri açığa çıkaran ve vatandaşlara şeffaflığı artıran bir iletişim altyapısı ile gerçekleştirilebilir. Kentsel bir IoT, aslında, ulaşım ve park etme, aydınlatma, kamu alanlarının gözetimi ve bakımı, kültürel mirasın korunması, çöp toplama, hastanelerin yönetimi gibi geleneksel kamu hizmetlerinin sunulmasında çeşitli faydalar sağlamaktadır.

Küresel dünyanın rekabetçi kentleri, rekabetin küresel düzeye taşınması ve sürdürülebilir olması için yapısal bir dönüşüm içerisindedirler. Sürekli değişen ve gelişen teknoloji ile birlikte kentler bu yapısal dönüşümü daha ileri götürerek “akıllı"laşmaktadır. Günümüzde daha da akıllı olma yolunda hızla ilerleyen kentler yeni nesil teknoloji ile daha fazla bütünleşmektedir. Böylece akıllı yollar, akıllı evler, akıllı araçlar, akıllı sensörler, akıllı cihazlar derken akıllı kentler milyar dolarları aşan yatırımlar sonucu IoT ile buluşarak daha da akıllı hale gelmektedirler. IoT tabanlı akıllı kent teknolojileri, kentlerde yaşanan hızlı nüfus artışı karşısında ihtiyaç duyulan alanlarda kentleri daha etkili, yaşanabilir ve yönetilebilir hale getirmektedir.

Hâlihazırda dünya nüfusunun \%50'sinden fazlası kentlerde yaşadığından, kent kaynakları ve altyapıları üzerinde önemli baskılar bulunmaktadır. Kentleri modernize etmek için bilgi ve iletişim teknolojilerinin kullanımı, kentsel mekanlardaki nüfus yoğunluğunun olumsuz etkilerini azaltan ve tüm vatandaşlar için yaşam kalitesini iyileştiren akıllı kentler kurmayı sağlamaktadır. Akıllı kentler, uçtan uca güvende tutulması gereken kritik verileri içeren ve kullanan büyük, karmaşık, dağıtılmış ve sürekli sistemlerdir. Bu yüzden akıllı kentler gittikçe daha fazla IoT özellikli ve IoT bağımlı hale gelmektedir. Bu noktada akıllı kentlerin güvenlikleri IoT protokollerinin güvenliğine bağlıdır.

Bugün gelişmiş ölçüm altyapısı ve diğer dijital teknolojilerdeki hızlı gelişmelerle birlikte verimli elektronik cihazlar ve IoT’e dayalı yerleşik sensörler sayesinde akıllı kentler daha akıllı hale gelmiş bulunmaktadır. Özellikle kent yönetiminde gelecek zamanlarda insan faktörünün büyük bir bölümünün IoT teknoloji ile bütünleşen yapay zekâ ile birlikte makinelerin alacağını tahmin etmek artık bir hayal olmaktan çıkmış bulunmaktadır. Teknolojinin kentsel yaşama adaptasyonu 
beraberinde birtakım avantajlar getirmekle birlikte birtakım olumsuzluklar da getirmektedir. Teknolojinin kent yaşamına adapte edilmesi ve bununla beraber IoT teknolojilerinin kullanılmaya başlanması salt avantajlar açısından ele alınırsa eksik bir yaklaşım olacağı şüphesizdir. Ancak unutulmamalıdır ki teknoloji ile buluşan kentler beraberinde kent yaşamını olumsuz etkileyebilecek veri güvenliği, veri gizliliği, siber saldırılar gibi bir takım yeni teknolojik sorunları da bünyesinde barındırma potansiyeline her zaman sahip olacaktır. Özellikle IoT ağlarından elde edilen ve taşınan, kritik olan akıllı kent verileri, kent işlevlerini engelleyebilecek, kişisel verileri çalabilecek ve yıkıcı zararlar verebilecek siber saldırıları önlemek için güvence altına alınmak zorundadır.

\section{References}

Akçomak, İ. S. (2018). Teknoloji ve İşgücü: Dijital Dönüşüm İşlerimize Ne Yapacak?. İktisat ve Toplum, 92, 66-69.

Albino, V., Berardi, U., \& Dangelico, R.M. (2015). Smart Cities: Definitions, Dimensions, Performance, and Initiatives. Journal of Urban Technology, 22(1), 3-21.

Aletà, N.B., Alonso, C.B. \& Ruiz, R.M.A. (2017). Smart Mobility and Smart Environment in the Spanish Cities. Transportation Research Procedia, 24, 163-170.

Arora, A., Khanna, A., Rastogi, A. \& Agarwal, A. (2017). "Cloud Security Ecosystem For Data Security And Privacy”. 7th International Conference on Cloud Computing, Data Science\&Engineering-Confluence, Amity University, Uttar Pradesh, ss. 288-292, India, Noida.

Baig, Z.A. (2014). "Securing the Internet of Things Infrastructure-Standards And Techniques". Proceedings of the 12thAustralian Information Security Management Conference, Cowan University, Joondalup Campus, ss. 75-81, Western Australia, Perth.

Baig, Z.A., Szewczyk, P., Valli, C., Rabadia, P., Hannay, P., Chernyshev, M., \& Peacock, M. (2017). Future Challenges For Smart Cities: Cyber-Security And Digital Forensics. Digital Investigation, 22, 1-11.

Balakrishna, C. (2012). "Enabling Technologies for Smart City Services and Applications". Sixth International Conference on Next Generation Mobile Applications, Services and Technologies, ss. 223-227, Paris.

Benevolo, C., Dameri, R.P. \& D’Auria, B. (2016). "Smart Mobility in Smart City: Action Taxonomy, ICT Intensity and Public Benefits" (Ed. Torre, T., Braccini, A.M. \& Spinelli, R.), Part of the Lecture Notes in Information Systems and Organisation Book Series, ss. 13-28, Springer International Publishing.

Bilici, Z. \& Babahanoğlu, V. (2018). Akıllı Kent Uygulamaları ve Konya Örneği. Akademik Yaklaşımlar Dergisi, 9(2), 124139.

Buhalis, D. \& Amaranggana, A. (2014). "Smart Tourism Destinations", Information and Communication Technologies in Tourism 2014, (Ed. Xianglis, Z. ve Tussyadiah, L.), Proceedings of the International Conference, 553-564, Dublin, Ireland.

Centenaro, M., Vangelista, L., Zanella, A. \& Zorzi, M. (2016). Long-range Communications In Unlicensed Bands: The Rising Stars In The IoT And Smart City Scenarios, IEEE Wireless Communications, 23 (5), 60-67.

Choudhary, S.K., Sathe, R.B. \& Kachare, A.E. (2017). Smart Cities Based on Internet of Things (IoT) - A Review, International Journal of Engineering Trends and Technology (IJETT), 48(8), 434-439.

Chourabi, H., Nam, T., Walker, S., Gil-Garcia, J.R., Mellouli, S., Nahon, K., .. \& Scholl, H.J. (2012). “Understanding Smart Cities: An Integrative Framework", 45th Hawaii International Conference on System Sciences, IEEE, ss. 22892297, USA, Maui.

Cisco (2015). IoT Threat Environment Report. Erişim Tarihi:05.01.2020 https://pdfs.semanticscholar.org/9120/50905a8533a525a10dcb9fe1dc303a53df9c.pdf.

Çakır, M. (2019). Yeni İletişim Teknolojilerinin Gelişimi Bağlamında Kent. Etkileşim, 2(3), 12-27. 
Damari, R.P. (2014). "Comparing Smart and Digital City: Initiatives and Strategies in Amsterdam and Genoa Are They Digital and/or Smart?" (Ed. Dameri, R.P. \& Sabroux, C.), Smart City-How to Create Public and Economic Value With High Technology in Urban Space, ss. 45-88, Springer, Switzerland.

Dameri, R.P. (2013). Searching for Smart City Definition: A Comprehensive Proposal. International Journal of Computers \& Technology, 11(5), 2544-2551.

Dameri, R.P., Benevolo, C., Veglianti E. \& Li, Y. (2019). Understanding Smart Cities as a Glocal Strategy: A Comparison Between Italy and China. Technological Forecasting\&Social Change, 142, 26-41.

Das, A., Sharma, S.C.M. \& Ratha, B.K. (2019). "The New Era of Smart Cities, From the Perspective of the Internet of Things” (Ed. Rawat, D.B. \& Ghafoor, K.Z.), Smart Cities Cybersecurity and Privacy, ss. 1-9, Elsevier.

Efe, A., Aksöz, E., Hanecioğlu, N. \& Yalman, Ş.N. (2018). Smart Security of IoT Against to DDoS Attacks. Uluslararası Yenilikçi Mühendislik Uygulamaları Dergisi, 2(2), 35-43.

Elvan, L. (2017), Akıllı Şehirler: Lüks Değil İhtiyaç. İTÜ Vakfı Dergisi, 77, 6-9.

Erdoğan, G. (2019). Akıllı Kent Göstergeleri ve Stratejileri. Yönetim Bilişim Sistemleri Dergisi, 4(2), 1-23.

Etüd Bilişim (2018). Akıllı Kent Teknolojileri. Erişim Tarihi: 28.12.2019, https://etud.com/akilli-kent-teknolojileri/.

Göçoğlu, V. (2020). Kamu Hizmetlerinin Sunumunda Dijital Dönüşüm: Nesnelerin İnterneti Üzerine Bir İnceleme. MANAS Sosyal Araştırmalar Dergisi, 9(1), 615-628.

Gündüz, M.Z. \& Daş, R. (2018). Nesnelerin İnterneti: Gelişimi, Bileşenleri ve Uygulama Alanları. Pamukkale Üniversitesi Mühendislik Bilimleri Dergisi, 24(2), 327-335.

Hammi, B., Khatoun, R., Zeadally, S., Fayad, A. \& Khoukhi, L. (2018). IoT Technologies for Smart Cities. IET Networks, $7(1), 1-13$.

Hancke, G., Silva, B., Hancke, G.P.Jr. (2012). The Role Of Advanced Sensing In Smart Cities. Sensors (Basel), 13(1), $393-$ 425.

ISO/IEC JTC 1 Information Technology (2015). Smart Cities Preliminary Report 2014. ISO, Switzerland.

Kaya Altay, İ. \& Gökgür, P. (2019). “Akıllı Şehir” Kavramının Orta Ölçekli Şehirlerin Gelişmesindeki Araçsallığı. Artium, $7(2), 115-123$.

Khalil, E. A., Özdemir: (2018). Nesnelerin İnternetine Genel Bir Bakış: Kavram, Özellikler, Zorluklar ve Fırsatlar. Pamukkale Üniversitesi Mühendislik Bilimleri Dergisi, 24(2), 311-326.

Khan, M. A., Iqbal, M. M., Ubaid, F., Amin, R. \& Ismail, A. (2016). Scalable and Secure Network Storage in Cloud Computing. International Journal for Computer Science and Information Security (IJCSIS), 14(4), 545-551.

Kılınç, A. (2019). Akıllı Kent: Öğreten Kentlerden Öğrenen Kentlilere. Gaziantep University Journal of Social Sciences, 18(3), 1101-1112.

Kumar, V. \& Dahiya, B. (2017). "Smart Economy in Smart Cities" (Ed. Kumar, V.), Smart Economy in Smart Cities, ss. 3-76, Advances in 21st Century Human Settlements, Springer, Singapore.

Letaifa, B. (2015). How to Strategize Smart Cities: Revealing the SMART Model. Journal of Business Research, 68(7), 1414-1419.

Löfgren, K. \& Webster, C. W. R. (2020). The Value of Big Data in Government: The Case of 'Smart Cities', Big Data \& Society, 1-14.

Madakam, S., Ramaswamy, R. \& Tripathi, S. (2015). Internet of Things (IoT): A Literature Review. Journal of Computer and Communications, 3, 164-173.

Mehmood, Y., Ahmad, F., Yaqoob, I., Adnane, A., İmran, M. \& Guizani, S. (2017). Internet-of-Things-Based Smart Cities: Recent Advances and Challenges. IEEE Communications Magazine, 55(9), 16-24. 
Mishra, N., Lin, C. C. \& Chang, H. T. (2015). A Cognitive Adopted Framework for IoT Big-Data Management and Knowledge Discovery Prospective. International Journal of Distributed Sensor Networks, 11(10), 1-12.

Mukundan, R., Madria, S. \& Linderman, M. (2014). Efficient Integrity Verification of Replicated Data In Cloud Using Homomorphic Encryption. Distrib Parallel Databases, 32(4), 507-534.

Örselli, E, Bayrakcı, E., \& Göksoy, B. (2019). “Teknolojinin Kent Yaşamına Yansıması: Akıllı Kentler Bağlamında Değerlendirme”, Uluslararası İktisadi ve İdari Bilimler Kongresi, ss. 233-245, Şırnak.

Örselli, E. \& Dinçer, S. (2019). Akıllı Kentleri Anlamak: Konya ve Barcelona Üzerinden Bir Değerlendirme. Uluslararası Yönetim Akademisi Dergisi, 2(1), 90-110.

Paskaleva, K., Evans, J., Martin, C., Linjordet, T., Yang, D. \& Karvonen, A. (2017). Data Governance in the Sustainable Smart City. Informatics, 4(41), 1-19.

Rajab, H. \& Cinkelr, T. (2018). "IoT based Smart Cities", 2018 International Symposium on Networks, ss. 1-4, Computers and Communications (ISNCC), Rome.

Suresh, P., Daniel, J. V., Parthasarathy, V., \& Aswathy, R. H. (2014). "A State of The Art Review on The Internet of Things (Iot) History, Technology and Fields of Deployment" 2014 International Conference on Science Engineering and Management Research (ICSEMR), ss. 1-8, Chennai.

Şahin, A. \& Yılmaz, F. H. (2019). Akıllı Kent Uygulamaları: Stockholm ve Bursa Üzerinden Bir Değerlendirme, Uluslararası Sosyal ve Beşerî Bilimler Araştırma Dergisi, 6(43), 2897-2915.

Terzi, F. \& Ocakçı, M. (2017), Kentlerin Geleceği: Akıllı Kentler. İTÜ Vakfı Dergisi, 77, 10-13.

Tomor, Z., Meijer, A., Michels A., \& Geertman, S. (2019). Smart Governance For Sustainable Cities: Findings from a Systematic Literature Review. Journal of Urban Technology, 26(4), 3-27.

Varol, Ç. (2017). “Sürdürülebilir Gelişme de Akıllı Kent Yaklaşımı: Ankara’daki Belediyelerin Uygulamaları”, Çağdaş Yerel Yönetimler, 1, 43-58.

Verma, A., Khanna, A., Agrawal, A. Darwish, A., \& Hassanien, A.E. (2019). "Security And Privacy in Smart City Applications And Services: Opportunities and Challenges" (Ed. Hassanien, A.E. \& Mohamed, E.), Cybersecurity and Secure Information Systems, ss. 1-15, Advanced Sciences And Technologies For Security Applications, Springer, Cham.

Yıldız, M. (2019). Bilgi Toplumu ve E-Devlet, Anadolu Üniversitesi Yayını, Eskişehir.

Zanella, A., Bui, N., Castellani, A., Vangelista, L., \& Zorzi, M. (2014). Internet of Things for Smart Cities. IEEE Internet of Things Journal, 1(1), 22-32.

Zygiaris, S. (2013). Smart City Reference Model: Assisting Planners to Conceptualize the Building of Smart City Innovation Ecosystems. Journal of the Knowledge Economy, 4(2), 217-231. 